\title{
Influencing factors upon the reliability of physical proficiency test
}

\author{
Dr. Khuraijam Sanatombi Devi ${ }^{1}$ Dr. R. K. Chandrakumar Singh ${ }^{2}$ \\ ${ }^{1}$ Assistant Professor, Department of Physical Education, Health Education \& Sports, D.M. College of Science, \\ Imphal, Manipur. \\ ${ }^{2}$ Assistant Professor, Department of Physical Education, Health Education \& Sports, D.M. College of Science, \\ Imphal, Manipur.
}

\begin{abstract}
The investigator has been selected (i) warm-up, (ii) motivation, and (iii) time of the day for physical performance as influencing factors of the reliability of physical proficiency test of (i) 30 feet shuttle-run, (ii) standing broad-jump, (iii) sit-ups for one minute. Eighty students of Bachelor Degree who are opted Physical Education, Health education and Sports subjects from different colleges affiliated to Manipur University were selected for this investigation. The Selection of the subjects was done purely on the basis of the specific purpose of the study and had certain level of physical proficiency so that all the subjects could perform all the variable test items of the study. After systematically analysed the data of the study it was found that the selected influencing measurement factors has been affected the reliability of the selected physical proficiency test.

Keywords: Proficiency, reliability, warm-up, motivation, 30 feet shuttle-run, standing broad-jump, and sit-ups for one minute.
\end{abstract}

\section{Introduction:}

For the past four/five decades, India has been made to develop a suitable infrastructures to improve upon prevailing standard of performance in international sports. Sports has advanced from relatively and unproductive beginning to the point at which the profession how has trained research worker striving to build a more scientific basis for sports. The importance attached to research in sports and activity is indicated by the increasing opportunity for advanced study in this field although such of present day research in sports is oriented. Problem of both theoretical and practical importance have challenged researchers. So that not only professional thinking was being advanced by many of the concept which have come from recent research are being put into practices.

Mall and their associates who conducted a study of comparative analysis of physical fitness with some physical and socio-psychological variables of school boys (13 to 15 years) possessing high academic achievement, suggest that more vigorous and compulsory physical education programme (which includes games and sports) should be provided for the students possessing high academic achievements, as games and sports contribute to certain intellectual qualities like-decision making, alert mind, ability to take decision promptly and quickly etc. These qualities can be utilized in daily life which ultimately increases efficiency. Zeigler Sport (sometimes viewed as a pleasurable diversion) and athletics (a highly competitive activity that brings a reward) are both part of the very life hood of our field and offer the possibility of great benefits and satisfaction to participants and coach alike. Johnson and Nelson, among the earliest reported sports skills tests were the Athletic Badge Tests devised in 1913 by the playground and Recreation Association of America. The test items pertained to the sports of volleyball, tennis, baseball, and basketball. In 1918 Hetherington developed tests for the California decathlon which made use of a graduated score plan. Robertson, Jennifer despite common knowledge that physical activity is beneficial, it has been reported that two third of Canadian children do not participate in regular physical activity (Crag, Russel, Cameron and Beauties, 1999). School-based interventions for children are promising because almost all children attend school. Research evaluating school based physical activity programme is at an early stage and there are many limitations in the literature. Three of the key limitations identified in the literature are related to (I) the effect of teacher training on programme evaluation outcomes, (2) lack of Canadian content and (3) The use of theoretical frameworks in programme development and evaluation. The purpose of this study was to assess the effect of participation in the activity. Physical activity programme on physical activity behavior intend to be physically active and physical activity self efficacy. In addition, the study addressed limitations in the literature by evaluating a Canadian programme including teacher training as an independent variable and using social cognitive theory as a from work for the evaluation. The subject, $252,4^{\text {th }}$ and $5^{\text {th }}$ grade students, were assigned to one of three treatment groupscomparison Active 8 only or Active 8 plus teacher training. Data collected from questionnaires before and after the 4 week treatment period showed that participation in Active 8 programme contributed to significant increases in physical activity self efficacy. In addition, the Active 8 plus teacher training group shared greater increase in physical activity behavior and physical activity Self-efficacy than the Active 8 only group. Bhola 
conducted a study of relationship of absolute leg length, foot and agility to jumping ability in volleyball using three strides rhythm. He conducted the on 25 male volleyball players for the study. The study found that the foot length, agility, dynamic power, as well as ankle flexibility had significant relationship with jumping ability using three strides rhythm whereas absolute leg length and relative leg length did not correlate significantly. Aver conducted a study on the relative effects of selected warm-up exercise on strength, agility, flexibility and power. The investigator had taken 90 college men as subject. They were tested in five volleyball classes before and after ten week of activity, involving 4 or 8 minutes of isometric activity per class period and found out the relative effects of selected warm-up exercise. Strength, agility, flexibility and power had no significant difference among treatment results except for dipping strength occurred. Tiva selected twenty-two women physical education majors at the University of California, Los Angeles, who were tested for arm strength and flexibility. The weaker arm was trained three times a week for four weeks with specific isometric exercises. The strength of the trained arm increased and the range of motion in extension increased slightly but the correlations between strength and flexibility were not significant.

The researcher felt that the greater performance in sports is mostly depend upon the fitness of the participants. To increase and develop the fitness level of the individual, it is necessary to know the individual's capability by some selected test items. But the measurement in selected test items might influence the reliability of the test. Good performance in any activity depends upon some certain factors. To understand the factors which influenced the performance of the individuals are more important for better performance in any activity. The aim of the present investigation is to analyze the influence of certain measurement factors upon the reliability of selected physical proficiency test.

\section{Method:}

The purpose of the study is to analyze the influence of certain measurement factors upon the reliability of selected physical proficiency test. Sports contribute towards social, mental, emotional and intellectual development. Physical performance is basically meant for increasing the efficiency of the body and human being need to be fit throughout the lives. The research scholar specifically selected only three test items. The three test items were: (a) 30 feet shuttle-run; (b) Standing broad-Jumps; and (c) Sit-up for one minute. Eighty students of Bachelor Degree who are opted Physical Education, Health education and Sports subjects from different colleges affiliated to Manipur University were selected for this investigation. The Selection of the subjects was done purely on the basis of the specific purpose of the study and had certain level of physical proficiency so that all the subjects could perform all the variable test items of the study. The necessary data were collected by administrating the test items for the chosen variables. All the tests were administered in the D.M. College Campus, Imphal West, Manipur. Before administering the test items, the subjects were briefed on the objectives and requirements of the various variables that were to be tested. The apparatus and procedure of the test were explained prior to the administration of the test items. The performance of all the test items of each subject on the measuring factors were recorded as respective scores of the morning as morning first, morning warm-up and morning motivation. The administration of the test items, measuring factors and their scores were taken in the evening on the same procedures as applied in the morning. Only two trials of all the test items on all the measuring factors were taken for this study.

The best of two trials of all the test items were recorded as the final score for statistical analysis of this study. The final scores of all the selected test items on the selected influencing factors were taken for statistical analysis and compared by using the following formula.

$$
\begin{gathered}
n=80, \quad \sum d_{i}=20.66, \quad \bar{d}=0.25825, \quad \sum d_{i}^{2}=7.8558, \quad s_{d}^{2}=\frac{\left(\sum d_{i}^{2}-n \bar{d}^{2}\right)}{n-1}=0.031903 \\
t=\frac{\bar{d}}{s_{d} / \sqrt{n}}=129320 \tau
\end{gathered}
$$

The correlations of all the test items were also calculated by using the following formula.

$$
r=\frac{\operatorname{Cov}(x, y)}{\sqrt{\operatorname{Var}(x) \operatorname{Var}(y)}}=\frac{\sum x y-n x y}{\left.\sqrt{\left(\sum x^{2}\right.}-n x^{2}\right)\left(\sum y^{2}-\overline{\left.x y^{2}\right)}\right.}
$$

\section{Result:}

The value of ' $t$-test' for the tests of morning warm up and morning motivation is alarmingly different. In the morning first the value of ' $t$-test' was 12.932 and that of the morning motivation was 16.128 . The value of ' $t$-test' for morning motivation was higher than the value of ' $t$-test' for morning warm up. The difference between them is glaring and significant. 
The ' $p$-value' for the morning warm up and the morning motivation was same. The data of various means, standard deviations, value of 't-test' and ' $p$-values' have been shown in the Table No.1.

Table No.1

Morning First t-test for comparison of the Scores (in sec.) of $30 \mathrm{ft}$ Shuttle Run

\begin{tabular}{|c|c|c|c|c|c|c|c|}
\hline \multicolumn{3}{|c|}{ First Variable } & \multicolumn{3}{|c|}{ Second Variable } & \multirow{2}{*}{ Value of t-test } & \multirow{2}{*}{$\mathrm{p}$-value } \\
\hline Variable & Mean & Standard Deviation & Variable & Mean & Standard Deviation & & \\
\hline \multirow{5}{*}{ Morning First } & \multirow{5}{*}{10.0534} & \multirow{5}{*}{0.7553} & Morning Warm Up & 9.7951 & 0.7205 & 12.932 & 0.000 \\
\hline & & & Morning Motivation & 9.6966 & 0.7186 & 16.128 & 0.000 \\
\hline & & & Evening First & 9.8596 & 0.7229 & 10.071 & 0.000 \\
\hline & & & Evening Warm Up & 9.6217 & 0.7496 & 15.585 & 0.000 \\
\hline & & & Evening Motivation & 9.5609 & 0.7589 & 11.389 & 0.000 \\
\hline
\end{tabular}

All the mean values of morning warm up, morning motivation, evening first, evening warm up and evening motivation were almost the same. The differences between them are negligible as those were in small fractions. Likewise the standard deviations had minor differences. However, the values of t-tests were somewhat different. The ' $p$-values' for all the above tests were equal. These different data have been shown in the Table No.2.

Table No.2

Morning Warm Up t-test for comparison of the Scores (in sec.) of $30 \mathrm{ft}$ Shuttle Run

\begin{tabular}{|c|c|c|c|c|c|c|c|}
\hline \multicolumn{3}{|c|}{ First Variable } & \multicolumn{3}{|c|}{ Second Variable } & \multirow{2}{*}{$\begin{array}{c}\text { Value of } \\
\text { t-test }\end{array}$} & \multirow[b]{2}{*}{ p-value } \\
\hline Variable & Mean & Standard Deviation & Variable & Mean & Standard Deviation & & \\
\hline \multirow{4}{*}{$\begin{array}{c}\text { Morning Warm } \\
\text { Up }\end{array}$} & \multirow{4}{*}{9.7951} & \multirow{4}{*}{0.7205} & Morning Motivation & 9.6966 & 0.7186 & 7.099 & 0.000 \\
\hline & & & Evening First & 9.8596 & 0.7229 & -3.938 & 0.000 \\
\hline & & & Evening Warm Up & 9.6217 & 0.7496 & 7.120 & 0.000 \\
\hline & & & Evening Motivation & 9.5609 & 0.7589 & 5.947 & 0.000 \\
\hline
\end{tabular}

The comparative study of morning motivation, evening first, evening warm up and evening motivation was again systematically carried out. In the morning motivation the 'mean' score was 9.6966. Evening first mean was a bit slower than the result of morning motivation. Evening warm up showed better results of 'mean' than morning motivation was much better than all of the other results. The standard deviations showed slight differences. The values of 't-tests' were all different and had shown wide gap results. However, the values of ' $t$ test' were very similar except evening motivation. The study results have been shown in the Table No.3.

Table No. 3

Morning Motivation t-test for comparison of the Scores (in sec.) of $30 \mathrm{ft}$ Shuttle Run

\begin{tabular}{|c|c|c|c|c|c|c|c|}
\hline \multicolumn{3}{|c|}{ First Variable } & \multicolumn{3}{|c|}{ Second Variable } & $\begin{array}{c}\text { Value of } \\
\text { t-test }\end{array}$ & p-value \\
\hline \multirow{3}{*}{ Morning Motivation } & \multirow{3}{*}{9.6966} & \multirow{3}{*}{0.7186} & Evening First & 9.8596 & 0.7229 & -7.860 & 0.000 \\
\hline & & & Evening Warm Up & 9.6217 & 0.7496 & 2.849 & 0.006 \\
\hline & & & Evening Motivation & 9.5609 & 0.7589 & 3.362 & 0.001 \\
\hline
\end{tabular}

The comparative study of evening first,. Evening warm up and evening motivation was again conducted carefully. The 'mean' of evening fist was 9.8596 and that of evening warm up was 9.6217. Evening warm up showed better results than evening first. However, the results of evening motivation were much better than the other two results. Standard deviations showed varied. The p-value for all the results was the same with zeroes. The analytical studies of the data are laid down in the Table No.4.

Table No. 4

Evening First, Evening Warm Up and Evening Motivation t-test for comparison of the Scores (in sec.) of $30 \mathrm{ft}$ Shuttle Run

\begin{tabular}{|c|c|c|c|c|c|c|c|}
\hline \multicolumn{3}{|c|}{ First Variable } & \multicolumn{3}{|c|}{ Second Variable } & \multirow{2}{*}{$\begin{array}{c}\text { Value of } t- \\
\text { test }\end{array}$} & \multirow[b]{2}{*}{ p-value } \\
\hline Variable & Mean & Standard Deviation & Variable & Mean & Standard Deviation & & \\
\hline \multirow{2}{*}{ Evening First } & \multirow{2}{*}{9.8596} & \multirow{2}{*}{0.7229} & Evening Warm Up & 9.6217 & 0.7496 & 10.000 & 0.000 \\
\hline & & & Evening Motivation & 9.5609 & 0.7589 & 7.395 & 0.000 \\
\hline $\begin{array}{c}\text { Evening Warm } \\
\text { Up }\end{array}$ & 9.6217 & 0.7496 & Evening Motivation & 9.5609 & 0.7589 & 1.791 & 0.077 \\
\hline
\end{tabular}


The correlation of the influencing factors - Warm Up, Motivation and time of the day for the test of 30 $\mathrm{ft}$ shuttle run for morning and evening sessions are shown in Table No. 5.

Table No. 5

Correlations Table for Score (in sec.) of $30 \mathrm{ft}$ Shuttle Run

\begin{tabular}{|c|c|c|c|c|c|c|}
\hline & Morning First & $\begin{array}{c}\text { Morning Warm } \\
\text { Up }\end{array}$ & Morning Motivation & Evening First & $\begin{array}{c}\text { Evening Warm } \\
\text { Up }\end{array}$ & Evening Motivation \\
\hline Morning First & 1.000 & 0.972 & 0.965 & 0.974 & 0.946 & 0.870 \\
\hline Morning Warm Up & 0.972 & 1.000 & 0.985 & 0.979 & 0.957 & 0.888 \\
\hline Morning Motivation & 0.965 & 0.985 & 1.000 & 0.967 & 0.95 & 0.882 \\
\hline Evening First & 0.974 & 0.979 & 0.967 & 1.000 & 0.959 & 0.882 \\
\hline Evening Warm Up & 0.946 & 0.957 & 0.950 & 0.959 & 1.000 & 0.919 \\
\hline Evening Motivation & 0.87 & 0.888 & 0.882 & 0.882 & 0.919 & 1.000 \\
\hline
\end{tabular}

All the selected students were tested again in the standing broad-jump the rules being the same with the other different tests. In this study the 'mean' obtained in the morning first was the lowest while comparing with morning warm up, morning motivation, evening first, evening warm up, morning motivation. Except the results of morning motivation and evening motivation all the other tests showed varied 'means'. There were minor differences in the standard deviations but not glaring. However the values of 't-tests' for all the tests were different but nevertheless the 'p-values' were all zeroes. The findings are shown in the Table No.6.

Table No. 6

Morning First t-test for comparison of the Scores (in inches) of Standing Broad Jump

\begin{tabular}{|c|c|c|c|c|c|c|c|}
\hline \multicolumn{3}{|c|}{ First Variable } & \multicolumn{3}{|c|}{ Second Variable } & \multirow{2}{*}{$\begin{array}{c}\text { Value of } \\
\text { t-test }\end{array}$} & \multirow[t]{2}{*}{ p-value } \\
\hline Variable & Mean & $\begin{array}{c}\text { Standard } \\
\text { Deviation }\end{array}$ & Variable & Mean & $\begin{array}{c}\text { Standard } \\
\text { Deviation }\end{array}$ & & \\
\hline \multirow{5}{*}{ Morning First } & \multirow{5}{*}{72.25} & \multirow{5}{*}{7.99} & Morning Warm Up & 79.91 & 8.00 & -25.517 & 0.000 \\
\hline & & & Morning Motivation & 8300 & 8.11 & -31.523 & 0.000 \\
\hline & & & Evening First & 75.61 & 7.93 & -29.796 & 0.000 \\
\hline & & & Evening Warm Up & 81.71 & 7.84 & -54.024 & 0.000 \\
\hline & & & Evening Motivation & 83.83 & 7.79 & -33.000 & 0.000 \\
\hline
\end{tabular}

The standing broad-jump test results are again studied according to morning warm up, morning motivation, evening first, evening warm up and evening motivation group. The 'mean' value for evening first was the lowest and the 'mean' value for the evening motivation was the highest closely followed by morning motivation. All the standard deviations were almost the same but there were wide differences in the values of ' $t$ tests'. The 'p-values' for all the tests were similar. This study is shown in the Table No.7.

Table No. 7

Morning Warm Up t-test for comparison of the Scores(in inches) of Standing Broad Jump

\begin{tabular}{|c|c|c|c|c|c|c|c|}
\hline \multicolumn{3}{|c|}{ First Variable } & \multicolumn{3}{|c|}{ Second Variable } & \multirow{2}{*}{$\begin{array}{c}\text { Value of } \\
\text { test }\end{array}$} & \multirow[t]{2}{*}{ p-value } \\
\hline Variable & Mean & $\begin{array}{c}\text { Standard } \\
\text { Deviation }\end{array}$ & Variable & Mean & $\begin{array}{c}\text { Standard } \\
\text { Deviation }\end{array}$ & & \\
\hline \multirow{4}{*}{$\begin{array}{c}\text { Morning Warm } \\
\text { Up }\end{array}$} & \multirow{4}{*}{79.91} & \multirow{4}{*}{8.00} & Morning Motivation & 83.00 & 8.11 & -8.329 & 0.000 \\
\hline & & & Evening First & 75.61 & 7.93 & 15.590 & 0.000 \\
\hline & & & Evening Warm Up & 81.71 & 7.84 & -6.623 & 0.000 \\
\hline & & & Evening Motivation & 83.83 & 7.79 & -11.022 & 0.000 \\
\hline
\end{tabular}

In order to get better ideas and concepts the test results of morning motivation, evening warm up and evening motivation are again studied. The 'mean' for the evening first was the lowest and the evening motivation was the highest. Morning motivation and evening motivation had very similar results. Morning motivation had the highest standard deviation but the rest had similar results. The value of ' $t$-test' for the evening first was the highest and the standard deviation for the evening motivation was the lowest. The p-value' for the evening motivation was highest among them. This study is shown in the Table No.8.

Table No.8

Morning Motivation t-test for comparison of the Scores(in inches) of Standing Broad Jump

\begin{tabular}{|c|c|c|c|c|c|c|c|}
\hline \multicolumn{3}{|c|}{ First Variable } & \multicolumn{3}{|c|}{ Second Variable } & \multirow{2}{*}{\begin{tabular}{|c|}
$\begin{array}{c}\text { Value of } \\
\text { test }\end{array}$ \\
\end{tabular}} & \multirow[t]{2}{*}{ p-value } \\
\hline Variable & Mean & Standard Deviation & Variable & Mean & Standard Deviation & & \\
\hline \multirow{3}{*}{ Morning Motivation } & \multirow{3}{*}{83.00} & \multirow{3}{*}{8.11} & Evening First & 75.61 & 7.93 & 22.505 & 0.000 \\
\hline & & & Evening Warm Up & 81.71 & 7.84 & 3.514 & 0.001 \\
\hline & & & Evening Motivation & 83.83 & 7.79 & -1.867 & 0.066 \\
\hline
\end{tabular}


The findings of evening first, evening warm up and evening motivation is studied separately. The 'mean' value for the evening first was the lowest and the 'mean' for evening motivation was the highest. However, the standard deviations showed very similar results. The values of 't-tests' were also very different. But the 'p-value' was similar. This study is illustrated in the Table No.9.

Table No.9

Evening First, Evening Warm Up and Evening Motivation t-test for comparison of the Scores (in inches) of Standing Broad Jump

\begin{tabular}{|c|c|c|c|c|c|c|c|}
\hline \multicolumn{3}{|c|}{ First Variable } & \multicolumn{3}{|c|}{ Second Variable } & \multirow{2}{*}{$\begin{array}{c}\text { Value of } \\
\text { t-test }\end{array}$} & \multirow{2}{*}{ p-value } \\
\hline Variable & Mean & $\begin{array}{c}\text { Standard } \\
\text { Deviation }\end{array}$ & Variable & Mean & $\begin{array}{c}\text { Standard } \\
\text { Deviation }\end{array}$ & & \\
\hline \multirow{2}{*}{ Evening First } & \multirow{2}{*}{75.61} & \multirow{2}{*}{7.93} & Evening Warm Up & 81.71 & 7.84 & -42.66 & 0.000 \\
\hline & & & Evening Motivation & 83.83 & 7.79 & -26.19 & 0.000 \\
\hline $\begin{array}{c}\text { Evening Warm } \\
\text { Up }\end{array}$ & 81.71 & 7.84 & Evening Motivation & 83.83 & 7.79 & -7.408 & 0.000 \\
\hline
\end{tabular}

The correlation of the influencing factors - Warm Up, Motivation and time of the day for the test of Standing Broad-Jump (in inches) for morning and evening sessions are shown in Table No. 10.

Table No. 10

Correlations Table for Score (in inches) of Standing Broad Jump

\begin{tabular}{|c|c|c|c|c|c|c|}
\hline & Morning First & $\begin{array}{c}\text { Morning Warm } \\
\text { Up }\end{array}$ & $\begin{array}{c}\text { Morning } \\
\text { Motivation }\end{array}$ & Evening First & $\begin{array}{c}\text { Evening Warm } \\
\text { Up }\end{array}$ & Evening Motivation \\
\hline Morning First & 1.000 & 0.944 & 0.928 & 0.992 & 0.981 & 0.921 \\
\hline Morning Warm Up & 0.944 & 1.000 & 0.915 & 0.952 & 0.953 & 0.919 \\
\hline Morning Motivation & 0.928 & 0.915 & 1.000 & 0.933 & 0.916 & 0.877 \\
\hline Evening First & 0.992 & 0.952 & 0.933 & 1.000 & 0.987 & 0.937 \\
\hline Evening Warm Up & 0.981 & 0.953 & 0.916 & 0.987 & 1.000 & 0.947 \\
\hline Evening Motivation & 0.921 & 0.919 & 0.877 & 0.937 & 0.947 & 1.000 \\
\hline
\end{tabular}

The eighty students were again rendered on sit-up tests according to the norms as stated in the foregoing paras. The value of 'mean' for the selected tools in the morning first was 40.08. After evening motivation the 'mean' value rose up to 48.8. Morning first and evening first showed only a slight different result whereas morning warm-up, morning motivation and evening warm up showed somewhat similar results. The differences in the standard deviation were minor and hence negligible. However, all the results of the values for all the above tests were .000. The findings are shown in the Table No. 11.

Table No.11

Morning First t-test for comparison of the Scores(in counts) of Sit Up

\begin{tabular}{|c|c|c|c|c|c|c|c|}
\hline \multicolumn{3}{|c|}{ First Variable } & \multicolumn{3}{|c|}{ Second Variable } & \multirow{2}{*}{$\begin{array}{c}\text { Value of } t- \\
\text { test }\end{array}$} & \multirow[t]{2}{*}{ p-value } \\
\hline Variable & Mean & $\begin{array}{c}\text { Standard } \\
\text { Deviation } \\
\end{array}$ & Variable & Mean & $\begin{array}{c}\text { Standard } \\
\text { Deviation } \\
\end{array}$ & & \\
\hline \multirow{5}{*}{ Morning First } & \multirow{5}{*}{40.08} & \multirow{5}{*}{6.63} & Morning Warm Up & 44.51 & 6.54 & -29.848 & 0.000 \\
\hline & & & Morning Motivation & 46.86 & 6.27 & -42.741 & 0.000 \\
\hline & & & Evening First & 41.58 & 6.63 & -11.169 & 0.000 \\
\hline & & & Evening Warm Up & 46.4875 & 6.4455 & -35.23 & 0.000 \\
\hline & & & Evening Motivation & 48.8 & 6.3254 & -43.187 & 0.000 \\
\hline
\end{tabular}

The 'mean' values of sit-ups in the morning warm up, morning motivation, and evening first, evening warm and evening motivation showed different results. The result of evening first was lowest and the results of evening motivation were the highest. The results of standard deviations were almost similar. However the values of 't-tests' were all zeroes. The various findings of the above sit-up tests are laid down in the Table No.12.

Table No. 12

Morning Warm Up t-test for comparison of the Scores(in counts) of Sit Up

\begin{tabular}{|c|c|c|c|c|c|c|c|}
\hline \multicolumn{3}{|c|}{ First Variable } & \multicolumn{3}{|c|}{ Second Variable } & \multirow{2}{*}{$\begin{array}{c}\text { Value of } \\
\text { t-test }\end{array}$} & \multirow[t]{2}{*}{ p-value } \\
\hline Variable & Mean & $\begin{array}{l}\text { Standard } \\
\text { Deviation }\end{array}$ & Variable & Mean & $\begin{array}{l}\text { Standard } \\
\text { Deviation }\end{array}$ & & \\
\hline \multirow{4}{*}{$\begin{array}{c}\text { Morning Warm } \\
\text { Up }\end{array}$} & \multirow{4}{*}{44.51} & \multirow{4}{*}{6.54} & $\begin{array}{c}\text { Morning } \\
\text { Motivation } \\
\end{array}$ & 46.86 & 6.27 & -22.298 & 0.000 \\
\hline & & & Evening First & 41.58 & 6.63 & 16.165 & 0.000 \\
\hline & & & Evening Warm Up & 46.4875 & 6.4455 & -11.392 & 0.000 \\
\hline & & & $\begin{array}{c}\text { Evening } \\
\text { Motivation }\end{array}$ & 48.8 & 6.3254 & -24.447 & 0.000 \\
\hline
\end{tabular}


The comparative finding of morning motivation, evening first, evening warm up and evening motivation is studied together. The 'mean' value of evening motivation had the highest results and evening first had the lowest while morning motivation and evening warm up had very similar results. The standard deviations for all these tests were almost same but the values of t-tests had wide differences. However, the 'p-values' for all these tests were zero. The above findings are illustrated in the Table No.13.

Table No. 13

Morning Motivation t-test for comparison of the Scores(in counts) of Sit Up

\begin{tabular}{|c|c|c|c|c|c|c|c|}
\hline \multicolumn{3}{|c|}{ First Variable } & \multicolumn{3}{|c|}{ Second Variable } & \multirow{2}{*}{$\begin{array}{c}\text { Value of } \\
\text { t-test }\end{array}$} & \multirow[t]{2}{*}{ p-value } \\
\hline Variable & Mean & $\begin{array}{c}\text { Standard } \\
\text { Deviation }\end{array}$ & Variable & Mean & $\begin{array}{c}\text { Standard } \\
\text { Deviation }\end{array}$ & & \\
\hline \multirow{3}{*}{ Morning Motivation } & \multirow{3}{*}{46.86} & \multirow{3}{*}{6.27} & Evening First & 41.58 & 6.63 & 27.111 & 0.000 \\
\hline & & & $\begin{array}{c}\text { Evening Warm } \\
\text { Up }\end{array}$ & 46.4875 & 6.4455 & 1.832 & 0.071 \\
\hline & & & $\begin{array}{c}\text { Evening } \\
\text { Motivation }\end{array}$ & 48.8 & 6.3254 & -9.652 & 0.000 \\
\hline
\end{tabular}

The test results of evening first, evening warm up and evening motivation are separately studied again. Here, the 'mean' value of evening first was only 41.58 and that of the evening motivation was 48.8. The standard deviation values for the three tests almost the same. The values of the tests were totally different but the 'p-values' were the same. These findings are shown in the Table No.14.

Table No. 14

Evening First, Evening Warm Up and Evening Motivation t-test for comparison of the Scores (in counts) of Sit Up

\begin{tabular}{|c|c|c|c|c|c|c|c|}
\hline \multicolumn{3}{|c|}{ First Variable } & \multicolumn{3}{|c|}{ Second Variable } & \multirow{2}{*}{$\begin{array}{c}\text { Value of } \\
\text { t-test }\end{array}$} & \multirow[t]{2}{*}{ p-value } \\
\hline Variable & Mean & $\begin{array}{c}\text { Standard } \\
\text { Deviation }\end{array}$ & Variable & Mean & $\begin{array}{l}\text { Standard } \\
\text { Deviation }\end{array}$ & & \\
\hline \multirow{2}{*}{ Evening First } & \multirow{2}{*}{41.58} & \multirow{2}{*}{6.63} & $\begin{array}{c}\text { Evening Warm } \\
\text { Up }\end{array}$ & 46.4875 & 6.4455 & -26.672 & 0.000 \\
\hline & & & $\begin{array}{c}\text { Evening } \\
\text { Motivation }\end{array}$ & 48.8 & 6.3254 & -35.625 & 0.000 \\
\hline $\begin{array}{c}\text { Evening } \\
\text { Warm Up }\end{array}$ & 46.4875 & 6.4455 & $\begin{array}{c}\text { Evening } \\
\text { Motivation }\end{array}$ & 48.8 & 6.3254 & -19.044 & 0.000 \\
\hline
\end{tabular}

The correlation of the influencing factors - Warm Up, Motivation and time of the day for the test of Sit-Up (in counts) for morning and evening sessions are shown in Table No. 15.

Table No. 15

Correlations Table for Score (in counts) of Sit Up

\begin{tabular}{|l|c|c|c|c|c|c|}
\hline & Morning First & $\begin{array}{c}\text { Morning Warm } \\
\text { Up }\end{array}$ & $\begin{array}{c}\text { Morning } \\
\text { Motivation }\end{array}$ & Evening First & $\begin{array}{c}\text { Evening } \\
\text { Warm Up }\end{array}$ & $\begin{array}{c}\text { Evening } \\
\text { Motivation }\end{array}$ \\
\hline Morning First & 1.000 & 0.984 & 0.98 & 0.969 & 0.977 & 0.962 \\
\hline Morning Warm Up & 0.984 & 1.000 & 0.97 & 0.969 & 0.965 & 0.962 \\
\hline $\begin{array}{l}\text { Morning } \\
\text { Motivation }\end{array}$ & 0.98 & 0.97 & 1.000 & 0.972 & 0.99 & 0.971 \\
\hline Evening First & 0.969 & 0.969 & 0.972 & 1.000 & 0.959 & 0.986 \\
\hline Evening Warm Up & 0.977 & 0.965 & 0.99 & 0.959 & 1.000 & 0.959 \\
\hline $\begin{array}{l}\text { Evening } \\
\text { Motivation }\end{array}$ & 0.962 & 0.962 & 0.971 & 0.986 & 0.959 & 1.000 \\
\hline
\end{tabular}

\section{Discussion:}

After recording the various data the research scholar made the selected subjects to take warm up in the form of exercise for about 15 to 20 minutes. After warming up the selected students were again put to the same test. The 'mean' obtained after warming up rose up to 61.0856. The result was even higher than the result of morning motivation. After completion of the test the selected subjects were again feedbacks in the form of motivation. The subjects were once again put to the same test as previously done. Surprisingly the results of the tests were much better than all the tests conducted on that day. Here the 'mean' rose up to 62.4513. The standard deviations for all the tests, both the first session and the second session, were slightly different but can be neglected. Likewise, the values of 't-test' for all the tests were also totally different. But the 'p-values' for all the said tests were zeroes.

The time taken for the chosen distance in the shuttle run was recorded with the help of stop-watch. The 'mean' for all the time taken by the subjects were calculated carefully and recorded. In the morning first the 'mean' was 10.0534. Then the subjects were given some exercises in the form of warm up. After about 15 to 20 minutes exercise the subjects were again tested in the same manner as done earlier. The subjects were allowed to 
perform their tests twice as done earlier and the better test result was recorded. The students performed a bit better than the morning first. The 'mean' for all the students were 9.7951. After warming up, the subjects improved somewhat. As soon as that the research scholar lectured and advised the subjects in the form of motivation. The subjects were motivated by using intrinsic method and then made to run the same distance like the other previous tests. There too, the subjects performed much better than both the earlier two tests. The 'mean' obtained after rendering motivation was 9.6966. The standard deviations for all the three types of the tests were also slightly differed. However, the 'p-value' for the entire test was the same.

At about 3 p.m. the second session started. In the same manner, as did in the first session, the research scholar made all the subjects to perform the same test twice. The 'mean' for all the time taken by the selected subjects was calculated and it was a bit better than the 'mean' of morning first. The subjects were given exercise of 15 to 20 minutes in the mode of warm up. Then all the subjects were once again exerted into the same testing. The 'mean' obtained after warming up was a little better than that of the result obtained in the morning motivation. There the 'mean' was 9.6217. As soon as that test was over the subjects were given feedbacks in the mode of motivation. For about a short motivation of about 15 minutes or so the subjects were once again put to the same test in the same manner as done in the previous session. The subjects performed much better than all the tests conducted earlier. There the 'mean' was 9.5609. Other results were also calculated minutely. The standard deviations for all the tests were of almost the same although there were slight differences. The values of 't-test' were totally different but the ' $p$-values' for all the tests were zeroes.

The third item for the test of the subjects was sit up. All the selected subjects were allowed to perform two tests each like it was done in the other test items and the better test performance was taken down as the final score. The fourth item began from 6 a.m. and ended at 9 a.m. Every subject was made to perform the test and the better result was noted down. The 'mean' for the morning first for the test item of sit up was 40.08 . Then the subjects were given 15 to 20 minutes warm up and then made to perform the same test items in the same manner as they were allowed earlier. The 'mean' was again noted down. After warming up, the 'mean' rose to 44.51. There was a significant increase in the performance. After that test the subjects were given feedbacks in way of motivation for about 15 minutes. Then all the subjects were once again made to perform their test in the same manner and procedure as earlier. The 'mean' was 46.86 . The overall performance for all the subjects improved after motivation. With that the first session for the fourth test item concluded. At 3 p.m. of the same day the second session for the fourth test item began. Every selected subject was made to perform the test in the lie manner as earlier. The 'mean' was again calculated and noted down under the evening first column. The 'mean' was 41.58 which was somewhat better than the 'mean' of morning first.

Then the subjects were given 15 minutes warm up. All the subjects were again made to perform the same test in the same style. The subjects performed much better after warming up. The 'mean' rose up to 46.4875 which was almost equal to the 'mean' of morning motivation. After the test of evening warm up all the subjects were given feedbacks for about 15 minutes. Then once again the subjects were made to perform the same test items in the like manner. The 'mean' was calculated and noted down. The performance of all the selected subjects excelled after motivation. The 'mean' rose up to 48.8 after motivation. The research scholar compared the other relevant data. The standard deviation for the entire test was almost the same except for minor differences. The values of 't-test' were all different but the ' $p$-values' for all were zeroes.

All the selected subjects were tested one by one. The style and procedure of performance for the subjects were carried out in the same manner with the other test items. Out of two performances for every subject the better score was selected as the data. The 'mean' for the morning first was 72.25. After the morning first test the subjects were given 15 minutes warm up. Then the subjects were again made to perform their tests in the same manner and the better scores were recorded accordingly. The 'mean' rose to 79.91 which was a bit better than the morning first. Just after that test the subjects were given feedbacks and motivated accordingly. After for about 15 minute's motivation the subjects were again made to perform the same test in the same style and procedure. The 'mean' rose up to 83.00 after motivation. The performances of all the subjects excelled much after motivation. Once again the selected subjects were made to perform their test items in the same way and manner as done in the morning first. The 'mean' was calculated and noted down in the column of evening first. The 'mean' was 75.61 which was better than the morning first. At the end of the evening first test the subjects were given a warm-up of 15 to 20 minutes. After warming up the subjects were again made to perform the same tests in the similar nature. The 'mean' was calculated and noted down. The 'mean' obtained after warming up test rose up to 81.71. Just after that test the subjects were briefed and thereby motivated for about 15 minutes. Then once again the subjects were made to perform the same test in the like manner and style. The 'mean' was once again calculated and noted down under the column of evening motivation. The 'mean' rose up to 83.83. After motivation the subjects performed much better than the other two tests. 


\section{Reference}

[1]. Mall T. and V.P. Paul, "Comparative Study Physical Fitness and Socio-psychological Variable of School Boys Possessing High Academic Achievement", SNIPES, Vol. 2, No. 3, Page 38.

[2]. Zeigler E.F. (1982), "Physical Fitness \& Sports : An Introduction", University of Western Ontario, London, Page 267.

[3]. Barry L. Johnson and Jack K. Nelson, "Practical Measurement for Evaluation in Physical education", Third Edition, Page 14.

[4]. Robertson, Jennifer Louise P.D., "The effect of Active 8 Participation Students Psychosocial Determinants of Physical Activity. "University of Toronto (Canada), 2003131 P.P. Order no. DANQ84726.

[5]. Vibha Bhola, "Relationship of Absolute Leg Length, Relative Leg Length, Foot Length, Dynamic Power, Ankle Flexibility and Agility to Jumping Ability to Volleyball using Three Strides Rhythm”. Unpublished Master's Degree Thesis, Jiwaji University, 1984.

[6]. Hampton Harvill Aver, "The Relative Effects of Selected Warm-up Exercises on Strength, Agility, Flexibility and Power". Completed research in Health, physical education and recreation". Vol.9: 1976 p.56.

[7]. Barnea Tiva, "Effect of Balanced Development on Flexibility of the Shoulder Girdle". M.S. in Physical Education (W. Massey. 1964). P.64. 